\title{
El aprendizaje: posibilidades teóricas para comprenderlo más allá de la escuela
}

Susana López Espinosa

lesusana@ hotmail.com

\section{Instituto Superior de Ciencias de la Educación del Estado de México}

Recibido:28-octubre-2019

Aceptado:15-enero-2020

\section{Resumen}

En este ensayo se propone repensar el aprendizaje escolar y, de manera específica, la formación profesional más allá de los enfoquecognitivos dominantes. La trama argumentativa en la revisión de dos perspectivas, las teorías de la cognición situada y las teorías de la actividad, se encamina a sostener que el aprendizaje, a diferencia de las visiones que lo reducen a absorber información, está presente en la participación cotidiana en las prácticas sociales, que participar y aprender son procesos mutuamente implicados. Si bien los énfasis de ambas perspectivas son distintos y corresponden a diversos campos de conocimiento, ambos de una u otra manera reconocen que aprender, pensar y conocer, son relaciones entre personas en actividad dentro de contextos histórica y culturalmente situados. En las teorías de la actividad continuamente se compara el aprendizaje en prácticas no escolares y en ámbitos escolares para des-cubrir posibilidades de hacer más trascendente éste último.

Palabras clave: aprendizaje, participación, actividad

\section{Introducción}

Las teorías sobre la enseñanza y el aprendizaje, han propuesto diferentes modelos para comprender y guiar el trabajo escolar, unos enfatizan el papel del profesor como elemento clave de los aprendizajes; otros destacan el papel protagónico de los estudiantes; otros más enfatizan un protagonismo compartido por profesor y alumnos. Estos últimos reflejan el dominio de los enfoques cognitivos dominantes en el último tercio del siglo $\mathrm{XX}$, proponen atender los procesos psicológicos que son clave en la comprensión de la acción educativa e 
instruccional del profesor y en el contenido y las formas de los aprendizajes de los estudiantes.

Más recientemente los modelos derivados de la perspectiva constructivo-cognitiva priorizan los procesos de construcción del aprendizaje y del conocimiento en el alumno, considerándolos procesos internos, individuales y solitarios; en cambio, las propuestas del socio-constructivas destacan otros factores como el grupo social, la comunidad de la que forma parte el alumno; en otra línea los enfoques constructivistas en los que también convergen las visiones cognitiva y social, aceptan el carácter individual e interno, pero niegan su carácter solitario.

Este contexto es útil para ubicar el análisis de dos propuestas que coinciden en reformular la concepción de aprendizaje y del sujeto que aprende, centrándose en el carácter mutuamente constitutivo del sujeto y la actividad en la que aprende. Dentro de éstas las teorías del aprendizaje situado y las comunidades de práctica señalan el carácter activo y contextualizado del conocimiento, proponen una visión de aprendizaje relacionada con la actividad que realizan personas específicas en circunstancias también específicas, vinculan la participación con la intervención activa de la persona en empresas sociales. Como otra posibilidad de análisis del aprendizaje se revisan planteamientos derivados de las teorías de la actividad desde una perspectiva cognitiva y sociocultural en los que se focaliza la cultura y los sistemas de actividad colectiva en los que se vinculan el contexto y los significados de los comportamientos aparentemente aleatorios.

La finalidad de este ensayo es contribuir a la valoración del carácter "social" y "colectivo" del conocimiento profesional, que no sólo cuenta con el sostén de las disciplinas académicas sino de aquél que se adquiere en la práctica profesional de los profesores que guían los procesos de formación profesional de los estudiantes y de las incipientes prácticas de éstos, de lo que se trata, como decía hace ya varios años María de Ibarrola $(1994$, pág, 18) al referirse a la relación de la escuela con el mundo del trabajo, es poner atención en una serie de elementos que sostienen y apuntalan el conocimiento que se procesa en la escuela, un sustrato invisible a los ojos de los diseñadores porque está constituido directa e 
indirectamente por los actores directos, indirectos y de referencia en el proceso educativo y porque tiene que trascender fuera de ella.

El ensayo se divide en dos partes, en la primera me ocupo del análisis de las teorías de la cognición situada, ubicándolas en una perspectiva que reconoce al aprendizaje como parte de prácticas sociales, destacando como categorías centrales las nociones de participación, práctica y comunidad. En la segunda presento las contribuciones recientes de las teorías de la actividad con énfasis en tres categorías que constituyen una red para comprender el aprendizaje: actividad, cultura y contexto.

\section{Las teorías de la cognición situada: participación, práctica y comunidad}

Los constructivismos con orientación sociocultural sitúan a la actividad como el concepto nuclear de la explicación del aprendizaje, reconocen la naturaleza social de la mente y de los procesos mentales; el interés pedagógico se centra en la dinámica de las relaciones sociales que se establecen entre los participantes, profesor y alumnos, durante la clase. Otras vertientes buscan las claves de la actividad y del aprendizaje en la participación de los alumnos en prácticas socioculturales más amplias que tienen su origen en entornos y en comunidades de práctica ajenos, en principio, al aula.

Estas últimas corrientes teóricas corresponden a lo que Baquero (2002) denomina el giro contextualista o situacional en la psicología del aprendizaje, el cual cuestiona las explicaciones del paradigma dominante centradas en el individuo como unidad de análisis y la forma en la que se trata homogéneamente a los sujetos sin considerar las condiciones de la situación en la que actúan.

El paradigma de la cognición situada está en oposición directa a la visión de ciertos enfoques de la psicología cognitiva y a innumerables prácticas escolares donde se asume, explícita e implícitamente, que el conocimiento puede abstraerse de las situaciones en las que se aprende y emplea. Por el contrario, los teóricos de la cognición situada parten de la premisa que el conocimiento es situado, es parte y producto de la actividad, el contexto y la cultura donde se desarrolla y utiliza (Díaz Barriga, F., 2003, p. 16).

Revista RedCA ISSN: 2594-2824 febrero-mayo 2020

Vol. 2 Núm. 6 
Vinculando la noción de aprendizaje significativo con las ideas de la visión sociocultural y en particular con el modelo de cognición situada, Frida Díaz Barriga (2003, 2006) plantea que si bien el desarrollo y aplicación de estas metodologías datan de hace varias décadas, lo que reviste interés es la manera en que se les revalora y recrea desde la perspectiva sociocultural y situada.

Dentro de este mismo paradigma, las teorías contemporáneas sobre la práctica social ofrecen una visión que permite considerar a la cognición más allá del laboratorio y la escuela. En esta misma línea Lave y Wenger (1991) elaboran una teoría del aprendizaje situado. Plantean que las personas aprenden participando en las actividades de una comunidad, al inicio en acciones que son aparentemente parciales, periféricas, triviales, hasta llegar a ser participantes completos.

La "participación periférica legítima" constituye un eje analítico, implica una participación parcial que aumenta progresivamente para avanzar hacia una mayor comprensión e integración a las actividades de una comunidad. El aprendiz no obtiene un cuerpo de conocimiento abstracto que pueda reaplicar de manera idéntica en otros momentos de la actividad o en otros contextos; él adquiere habilidades de conocimiento que le permiten orientarse en la actividad y seguir participando. Los autores enfatizan la idea de que la participación implica cambios en el conocimiento y la acción; y esa participación en la vida cotidiana es concebida como un proceso cambiante de comprensión en la práctica, lo cual es considerado como aprendizaje.

El énfasis de Lave y Wenger está en el aprendizaje situado, posteriormente Wenger (2001) propone una teoría social del aprendizaje en la cual el énfasis se desplaza a las comunidades de práctica. Éstas no son unidades independientes, se desarrollan dentro de contextos más amplios, sus límites no coinciden necesariamente con los límites institucionales; el reconocimiento de quien es miembro de una comunidad se da más por la cercanía en las acciones, por las actividades y responsabilidades que se comparten, por los significados mutuamente comprensibles que porque oficialmente se determine quién es miembro de una comunidad y quién no. 
En una comunidad de práctica puede haber un conjunto de prácticas interrelacionadas, las cuales comparten artefactos, tienen tareas relacionadas, dirigen sus acciones hacia finalidades comunes, poseen discursos y estilos similares, están cerca o en un mismo lugar.

Wenger (2001) sintetiza su teoría planteando que el aprendizaje, cualquiera sea su forma, modifica quienes somos, cambiando nuestra capacidad de participar, pertenecer, de negociar significados; esta capacidad se configura socialmente en relación con las prácticas y las comunidades. Lave (2001) enfatiza que el aprendizaje es un proceso de final abierto en el que intervienen una infinidad de circunstancias interrelacionadas. Ambos cambian el foco de análisis del aprendizaje visto como adquisición de conocimiento al de aprendizaje como reinvención del conocimiento; la reinvención implica considerar las aportaciones de distintas personas, las actividades múltiples así como las metas y circunstancias diferentes que se tienen al solucionar un problema.

\section{Las teorías de la actividad: cultura y contexto}

En esta parte interesa mirar teorías que desde distintos enfoques explican el aprendizaje a través de una red conformada por la actividad y la cultura, diferenciando los ámbitos no escolares y escolares. Como se verá, desde distintas ópticas la actividad constituye una categoría nodal que sintetiza el interés en reconocer que el conocimiento no es una cosa inerte radicado en la mente humana, sino algo en continua transformación de acuerdo a los requerimientos de las acciones que son parte de prácticas sociales.

La otra categoría nodal que anuda estas teorías es la cultura, en la que se condensan conocimientos, artefactos, significados y metas comunes, en la que lo individual y lo social sólo constituyen extremos en la representación de una relación que en realidad es difícil descomponer. En la noción de contexto se sintetizan el conocimiento y la acción, lo individual y lo social, las capas históricas sobrepuestas en una práctica social y sus potencialidades futuras.

Para estas teorías la mente y la cultura son mutuamente constitutivas y, por 
tanto, inseparables. La cultura incluye desde esta óptica psicocultural del desarrollo las tradiciones y las prácticas sociales, ambas regulan la mente humana, en este sentido Michael Cole afirma:

\begin{abstract}
"Desde hace mucho tiempo la noción de cultura ha incluido una teoría general de la manera en que se puede promover el desarrollo: crear un entorno artificial en el que se aportan a los organismos más jóvenes condiciones óptimas para el crecimiento. Esto requiere instrumentos, perfeccionados a lo largo de generaciones y diseñados para la tarea especial que deben desarrollar“ (Cole, 1999, p. 143).
\end{abstract}

En la convergencia de los aportes psicoculturales, históricoculturales y transculturales que focalizan los procesos cognoscitivos hay un reconocimiento implícito de la dimensión histórica de la cultura y de su carácter estructurante en la integración social de las nuevas generaciones, estas visiones enfatizan cómo las prácticas sociales y particularmente las prácticas de trabajo constituyen senderos seguros para lograr altos niveles de la actividad, distinguen los procesos de aprendizaje en los ámbitos de trabajo y en la institución escolar.

Scribner (1985), por ejemplo al comparar el aprendizaje mediante la resolución de problemas que realizan cotidianamente los trabajadores de una lechería y estudiantes de educación profesional, analiza cómo los estudiantes están sujetados a procedimientos de cálculo que no podrían ser aplicados efectivamente a problemas de matemáticas no-aula. Por el contrario, los trabajadores de la lechería lechería utilizaron instrumentos que existen dentro de su ambiente de trabajo, como unidades envasadas y cajones de leche, para responder efectivamente a problemas matemáticos. El análisis de Sylvia Scribner se orienta comparar la utilidad de las estrategias que se enseñan en el aprendizaje profesional-formal y las que se emplean en escenarios de trabajo.

En esta misma de análisis Bruner (1995) señala que en las formas de transmisión empleadas en las sociedades indígenas los procesos de aprendizaje están implicados en los contextos de acción. La diferencia estriba no solamente en que las sociedades indígenas se vienen abajo fulminantemente cuado se modifican sus pautas de acción, sino en que la institución escolar cumple una función de dotar a los conocimientos y destrezas de una forma 
más simbólica, abstracta y verbal.

Si bien Scribner (1985) pone el acento en las estrategias de aprendizaje, Bruner (1995) llama la atención sobre otro asunto, "el vehículo de transmisión de la cultura." Al comparar la escuela en lo que él denomina una sociedad tecnificada, con las formas de transmisión empleadas en las sociedades indígenas, destaca que en éstas los procesos de enseñanza y de aprendizaje se dan en el contexto de la acción, lo que implica la participación continua en actividades, el dominio de muy diversos artefactos y conocimientos, mientras que en la institución escolar los conocimientos y destrezas se ofrecen una forma más simbólica, abstracta y verbal.

En lo conceptual y en la práctica el contexto aparece coimplicado con la actividad y la cultura. Éste es un término sobre el cual se discute ampliamente en las últimas décadas, las discusiones oscilan entre visiones que lo conciben como algo ajeno a la influencia individual y concepciones que lo consideran como algo que puede ser creado a voluntad de dos o más personas que intractúan, con prescindencia de las prácticas y las condiciones materiales y sociales de una cultura dada, para los teóricos de la actividad, los contextos no son ni contenedores ni espacios empíricos creados situacionalmente, son sistemas de actividad que integran en todo unificado al sujeto, al objeto y a los instrumentos (herramientas materiales, signos y símbolos). (Engeström, 2001).

Desde esta perspectiva vida de los contextos, es discontinua, además de la acumulación y el crecimiento, hay crisis, perturbaciones y transformaciones, existen continuos procesos de construcción: las personas no sólo usan los instrumentos, también, a sabiendas o no, los renuevan y desarrollan constantemente; no sólo obedecen reglas, sino que también las moldean y reformulan. Los contextos no son unidades homogéneas, por el contrario, se componen de una multitud de elementos, acciones, voces y puntos de vista a menudo dispares. Esta multiplicidad puede entenderse como una acumulación de capas históricas, así como de brotes y retoños de su posible futuro. En estos sedimentos y brotes se encuentran las formas de interacción que se establecen entre los individuos, los modelos mentales de los individuos y las herramientas materiales. 
En el análisis de estas perspectivas teóricas lo que intento es destacar es que actividad y prácticas sociales situadas integran a la cognición y al aprendizaje, y que la escuela, al ignorar la naturaleza situada de la cognición, está lejos de propiciar que los estudiantes logren el conocimiento trascendentes y transferibles. En este sentido Bruner señala:

Hay una serie de cosas concretas en las que debe actuar una sociedad a fin de instruir a sus jóvenes. Lo que debe hacer es convertir su objeto de conocimiento, sean estos desterezas, sistemas de creencias o conjuntos estructurados de conocimiento, en un formato que pueda ser dominado porlos no indiciados (Bruner, 1995, p. 161).

Este autor también reconoce que la inocuidad para entender campos de conocimiento relacionados con la ciencia y las matemáticas no depende de incapacidades humanas sino de no saber cómo enseñarlas, también recomienda dada la cantidad limitada de tiempo que existe para el aprendizaje, que nos ocupemos por ahorrar al sujeto todo aprendizaje innecesario y por hacer hincapié en su transferencia.

\section{Conclusión}

Cierro con una idea con la que introduje el artículo, de lo que se trata, a partir de las propuestas de la cognición situada y del paradigma sociocultural, es de poner atención en una serie de elementos que sostienen y apuntalan el conocimiento que se procesa en la escuela, en los conocimientos situados más allá de las disciplinas académicas (sin descuidar éstas, claro está), aquéllos que conforman ese sustrato invisible al que alude De Ibarrola (1994) constituido directa e indirectamente por los actores directos, indirectos y de referencia en el proceso educativo que se despliega en todo proceso de formación profesional, sustrato en el que en cada institución se concretiza una manera de entender la profesión y de guiar las primeras etapas de participación periférica de los estudiantes a través del uso práctico de artefactos, así como de su posicionamiento y participación en acividades situadas en ambientes sociales estructurados culturalmente.

\section{Referencias}

Baquero, R. (2002). "Del experimento escolar a la experiencia educativa. La transmisión educativa desde una perspectiva psicológica situacional." En Perfiles Educativos, 
Vol. XXIV, núms. 97-98. Centro de Estudios sobre la Universidad, Universidad Nacional Autónoma de México.

Bruner, J. (1995). Actos de Significado. Más allá de la Revolución Cognitiva. Madrid: Alianza editorial.

Cole, M. (1999). Psicología Cultural. Una disciplina del pasado y del futuro. Madrid: Morata.

De Ibarrola, M. (1994b). La articulación entre la escuela técnica del nivel medio y el mundo del trabajo en México. ¿Espacios vacíos de la gestión educativa? Documentos DIE 27. México: IPN.

Díaz Barriga, F. (2003). "Cognición situada y estrategias para un aprendizaje significativo". En Revista Electrónica de Investigación Educativa. Vol. 5, núm. 2

Díaz Barriga, F. (2006). Enseñanza situada: Vínculo entre la escuela y la vida. México: Mc Graw Hill.

Engeström, Ÿ. (2001) "Los estudios evolutivos del trabajo como punto de referencia de la teoría de la actividad: El caso de la práctica médica de la asistencia básica”. En S. Chaiklin y J. Lave (Comps.), Estudiar las prácticas. Perspectivas sobre actividad y contexto. Buenos Aires: Amorrortu.

Lave, J. (1988). Cognition in Practice. Cambridge: Cambridge University Press. Ed. en español de 1991 con el título Cognición en la práctica. Barcelona: Paidós Ibérica.

Lave, J. (2001). "La práctica del aprendizaje”. En S. Chaiklin y J. Lave (Comps.), Estudiar las prácticas. Perspectivas sobre actividad y contexto. Buenos Aires: Amorrortu.

Lave \& Wenger (1991). Situated learning. Legitimate peripheral participation. New York: Cambridge University Press.

Rogoff, B. (1993). Aprendices del pensamiento. El desarrollo cognitivo en el contexto social. Barcelona: Paidós. 
Scribner, S. (1985). On the job training: A case study. New York: Laboratory for Cognitive Studies of Work.

Wenger, E. (2001). Comunidades de práctica. Aprendizaje, significado e identidad. Barcelona: Paidós.

Wertsch, J. (1993). Voces de la mente. Madrid: Aprendizaje Visor. (1 $1^{\text {a }}$ ed. en inglés, 1991). 